\title{
Kajian Kuat Tekan Beton Ringan Menggunakan Karang, Pasir Pantai, dan Bahan Tambah Polymer Concrete (Polcon)
}

\author{
Herry Yulianto ${ }^{1}$, Sylviana Dewi Sulaksono ${ }^{2}$ \\ email: ${ }^{1}$ herryyulianto228@yahoo.co.id \\ Program Studi Teknik Sipil, Fakultas Teknik, Unika Soegijapranata, Semarang, Universitas Katolik \\ Soegijapranata; Jl. Pawiyatan Luhur IV/1 Bendan Dhuwur Semarang 50234, 024-8441555
}

\begin{abstract}
Abstrak
Masyarakat yang tinggal di daerah pantai sangat berlimpah dengan material pasir pantai dan karang yang sudah mengalami pemutihan. Material karang yang sudah mengalami pemutihan dan pasir pantai mungkin dapat digunakan sebagai material pembuat beton dengan ditambah dengan admixture polymer concrete untuk menambah kuat tekan beton tersebut. Beton dengan material agregat kasar karang, agregat halus pasir pantai, dan menggunakan bahan tambah polymer concrete merupakan beton ringan dengan berat massa rata-rata 1966,737 kg/m3 untuk benda uji berumur 7 hari, 1856,688 $\mathrm{kg} / \mathrm{m} 3$ untuk benda uji berumur 14 hari, dan $1828,025 \mathrm{~kg} / \mathrm{m} 3$ untuk benda uji berumur 28 hari. Agregat halus yang digunakan merupakan pasir pantai yang memiliki modulus kehalusan 3,96 dan termasuk jenis pasir kasar, selain itu pasir pantai memiliki persen penyerapan air yaitu $42,166 \%$, berat jenis dalam kondisi kering 1,324 gr/cm3, berat jenis saat kondisi SSD (Saturated Surface Dry) sebesar 1,883 gr/cm3, dan memiliki kadar air sebesar 15,373\%. Agregat kasar karang memiliki keausan $93,04 \%$ setelah melalui uji los angeles. Penggunaan admixture polymer yang digunakan pada penelitian ini adalah $0 \%, 2 \%$, dan 4\%. Penelitian ini menggunakan semen PPC (Portland pozooloan cement). Air yang digunakan menggunakan air yang diambil dari sumur artetis laboratorium bahan bangunan Teknik Universitas Katolik Soegijapranata. Benda uji beton akan di tes kuat tekan menggunakan mesin UTM ( Universal Testing Machine). Beton dengan material karang, pasir pantai, dan bahan tambah polymer concrete merupakan beton ringan yang hanya dapat digunakan untuk komponen non struktur sebuah bangunan.
\end{abstract}

Kata kunci : Beton, Pasir Pantai, Karang, Polymer Concrete, Kuat Tekan Beton

\begin{abstract}
Communities living in coastal areas are very abundant with bleached beach sand and coral material. Coral material that has undergone bleaching and beach sand may be used as a material for making concrete with added polymer concrete admixture to increase the compressive strength of the concrete. Concrete with coarse aggregate material of coral, fine aggregate of beach sand, and using polymer concrete added material is lightweight concrete with an average mass weight of 1966,737 kg / m3 for 7-day-old specimens, $1856,688 \mathrm{~kg} / \mathrm{m} 3$ for aged specimens 14 days, and 1828,025 kg / 33 for 28-day old specimens. Fine aggregate used is beach sand which has a fineness modulus of 3.96 and is included in the type of coarse sand, besides that beach sand has a water absorption percentage of $42.166 \%$, specific gravity in dry conditions $1.324 \mathrm{gr} / \mathrm{cm} 3$, specific gravity when SSD (Saturated Surface) Dry) of 1,883 $\mathrm{gr} / \mathrm{cm} 3$, and has a moisture content of 15,373\%. Coarse coral aggregate has 93.04\% wear after going through the Los Angeles test. The use of polymer admixture used in this study was 0\%, 2\%, and 4\%. This study uses PPC cement (Portland pozooloan cement). The water
\end{abstract}


used uses water taken from artesian wells of Soegijapranata Catholic University Technical Building Materials Laboratory. Concrete test specimens will be tested using compressive strength UTM (Universal Testing Machine). Concrete with coral material, beach sand, and polymer concrete added material is lightweight concrete that can only be used for non-structural components of a building.

Keywords: Concrete, Beach sand, Coral, Polymer concrete, Concrete Compressive Strength

\section{PENDAHULUAN}

\subsection{Latar Belakang}

Beton merupakan material yang sering digunakan dalam bidang konstruksi. Beton digunakan karena memiliki beberapa kelebihan, yaitu bahan penyusun yang mudah didapat, harga lebih terjangkau, serta memiliki kuat tekan tinggi dan tahan terhadap suhu tinggi. Pada perkembangannya beton mengalami modifikasi pada komponen penyusunannya. Modifikasi ini dilakukan agar pembuatan beton menjadi ramah lingkungan.

Karang yang dipilih sebagai pengganti agregat kasar adalah karang yang mengalami pemutihan, karena jumlah karang tersebut dari tahun ke tahun semakin bertambah dan karang merupakan sumber daya yang dapat diperbarui. Selain mengganti agregat kasar dengan karang, Pasir pantai juga dipilih sebagai bahan alternatif untuk mengganti pasir darat yang persediaannya terbatas. Penambahan Polymer Concrete (Polcon) juga dilakukan agar nilai kuat tekan beton menjadi lebih tinggi.

\subsection{Rumusan Masalah}

Rumusan masalah penelitian ini adalah berapa konsentrasi Polymer Concrete untuk membuat beton dengan menggunakan karang, pasir pantai dengan minimal kuat tekan 24,9 MPa.

\subsection{Tujuan Penelitian}

Tujuan penelitian ini untuk mengetahui nilai kuat tekan beton modifikasi dengan menggunakan karang dalam kondisi dipecahkan, pasir pantai, dan admixture polymer concrete (Polcon) dengan konsentrasi sebesar 0\%, 2\%, $4 \%$.

\subsection{Manfaat Penelitian}

Manfaat yang diharapkan ada pada penelitian ini untuk perkembangan inovasi beton, antara lain:

a. Memanfaatkan limbah karang sebagai bahan pembuatan beton,

b. Menjadi bahan alternatif bagi penduduk pantai untuk membuat beton.

\subsection{Pembatasan Masalah}

Batasan masalah pada penelitian ini adalah:

a. Bahan yang digunakan dalam pembuatan beton :

a.1. Semen menggunakan Portland Pozoloan/ Portland Pozzoloan Cement (PPC) (semen hidrolis)

a.2. Air yang digunakan diambil dari sumur artetis Laboratorium Bahan Bangunan Teknik Sipil Fakultas Teknik Universitas Katolik Soegijapranata.

a.3. Benda uji yang digunakan adalah silinder berdiameter $10 \mathrm{~cm}$ dan tinggi $20 \mathrm{~cm}$ berjumlah 27 buah. Benda uji memiliki 3 variasi yang berbeda dengan masing-masing variasi memiliki 3 sampel.

a.4. Agregat kasar yang digunakan adalah karang dari pantai Jepara yang dipecahkan sehingga berukuran $5 \mathrm{~mm}-40 \mathrm{~mm}$.

a.5. Agregat halus yang digunakan adalah pasir pantai putih dari Pantai Jepara. 
a.6. Bahan tambah yang digunakan adalah polymer concrete dengan konsentrasi $0 \%, 2 \%, 4 \%$ dari volume air yang digunakan.

b. Pengujian kuat tekan beton pada saat beton berumur 7, 14, 28 hari.

c. Pengujian kuat tekan silinder dilakukan di Laboratorium Bahan Bangunan Teknik Sipil Fakultas Teknik Universitas Katolik Soegijapranata.

d. Penelitian ini merupakan penelitian yang dilakukan dalam skala laboratorium.

e. Metode perhitungan mix design mengacu ACI 211.11-91.

f. Mutu beton yang direncanakan adalah 24,9 MPa.

\section{METODE PENELITIAN}

\subsection{Uraian Umum}

Pada penelitian ini terdiri dari beberapa tahap sebagai upaya untuk mengumpulkan data yang akan dianalisis. Tahap-tahap dimulai dari persiapan dan diakhiri dengan kesimpulan dan saran.

\subsection{Tahapan Penelitian}

Pada penelitian ini terdiri dari beberapa tahap. Tahap-tahap penelitian tersebut dijelaskan pada poin-poin berikut:

\subsubsection{Tahap I}

Tahap ini dimulai dari persiapan material dan pada tahap akhir adalah perencanaan mix design. Penjelasan untuk masing-masing tahap adalah sebagai berikut:

a. Studi Literatur

Literatur yang digunakan pada penelitian ini adalah jurnal yang diunduh dari internet, buku yang terdapat di perpustakaan, dan tugas akhir. Literatur yang digunakan berhubungan dengan penelitian ini.

\section{b. Pengadaan Material}

Material-material yang digunakan adalah pasir pantai (agregat halus), dan karang (agregat kasar) yang berasal dari Pantai Jepara, polymer concrete (zat admixture), semen, dan air yang berasal dari sumur artetis Laboratorium Bahan Bangunan Teknik Sipil Fakultas Teknik Univesitas Katolik Soegijapranata.

c. Pengujian Material

Pengujian material yang dilakukan adalah:

c.1. Analisis saringan agregat halus dan agregat kasar.

Pengujian ini dilakukan dengan berdasarkan SNI ASTM C136:2012.Tujuan pengujian ini adalah mengetahui pembagian gradasi butiran agregat halus dan kasar, dan modulus kehalusan. Gradasi dan modulus merupakan acuan tingkat kemudahan pengerjaan beton.

c.2. Analisis agregat keausan agregat kasar dengan mesin abrasi Los Angeles.

Pengujian ini mengacu mengacu SNI 03-2417-199. Tujuan dari uji ini adalah menemukan ketahanan agregat kasar terhadap keasusan dengan menggunakan mesin abrasi los angeles dan mengetahui nilai keausan agregat kasar yang dinyatakan dengan lolos saringan no 12 (diameter $1,7 \mathrm{~mm}$ ) terhadap berat semula (dalam persen).

c.3. Analisis kadar air agregat kasar dan halus.

Peraturan yang digunakan sebagai acuan adalah SNI 03-1970-1990. Tujuan pengujian ini adalah mengetahui kadar air yang dapat diserap oleh material agregat kasar dan halus yang digunakan. 
c.4. Analisis berat jenis dan penyerapan agregat halus.

Pengujian ini mengacu pada peraturan SNI 1970:2008.

Pengujian ini dilakukan dengan cara menghitung berat benda uji dibagi dengan selisih dari berat air dan berat pasir di dalam air.

c.5. Pengujian komposisi unsur dalam koral dan pasir pantai.

Pengujian komposisi unsur dalam koral dan pasir pantai ini menggunakan uji SEM EDX. SEM EDX merupakan singkatan dari Scanning Electron Microscope and Energy Dispersive X-ray Spectroscopy. Pengujian tersebut menggunakan alat fine coater. Alat tersebut digunakan untuk melapisi material yang bersifat non konduktor dengan lapisan metal. Pengujian ini dilakukan di Unit Pelaksana Teknis (UPT) Laboratorium Terpadu Undip.

d. Persiapan Benda Uji

Alat-alat yang digunakan untuk melakukan penelitian ini adalah silinder dengan diameter $10 \mathrm{~cm}$ dan tinggi 20 $\mathrm{cm}$, concrete mixer, satu set alat yang digunakan dalam uji slump test.

e. Perencanaan Mix Design

Tahap selanjutnya adalah perencanaan mix design. Perencanaan mix design dilakukan dengan mengacu ACI 211.191 ini dilakukan setelah semua material yang diuji memenuhi persyaratan yang telah ditentukan.

\subsubsection{Tahap II}

Pada tahap ini dimulai dengan pembuatan benda uji dan tahap terakhir adalah pembahasan dari data-data yang didapatkan. Berikut adalah pembahasan dari masing-masing tahap: a. Pembuatan Benda Uji

Pembuatan benda uji terdiri dari pembuatan campuran beton (mixing), uji slump test, dan perawatan beton (curing).

Langkah-langkah pencampuran beton akan dijelaskan secara lebih detail sebagai berikut:

a.1. Agregat kasar yang berupa koral dipecah menggunakan palu,

a.2. Kemudian disaring dengan menggunakan saringan,

a.3. Agregat kasar dan halus dicampur dengan perbandingan yang telah ditetapkan sebelumnya,

a.4. Semen dimasukkan ke dalam adukan tersebut dan dicampur kembali agar adukan dan semen dapat tercampur dengan baik,

a.5. Air dimasukkan ke dalam adukan,

a.6. Polymer concrete dimasukkan ke dalam adukan. Konsentrasi polymer yang ditambahkan bervariasi meliputi $0 \%, 2 \%$, dan $4 \%$,

a.7. Setelah adukan tercampur dengan baik, langkah selanjutnya adalah slump test dilakukan,

a.8. Setelah dilakukan slump test, langkah selanjutnya adalah adukan dimasukkan ke dalam cetakan benda uji,

a.9. Cetakkan tersebut kemudian diletakkan di tempat yang tidak terkena sinar matahari selama kurang lebih 1 hari.

a.10. Setelah 1 hari, benda uji dikeluarkan dari cetakkan dan dimasukkan ke dalam bak perendaman untuk perawatan hingga berumur 7, 14, dan 28 hari. Benda uji yang dibuat pada tahap ini berjumlah 27 buah. Benda uji berbentuk silinder dengan diameter $10 \mathrm{~cm}$ dan tinggi $20 \mathrm{~cm}$. 
b. Pengujian Benda Uji

Pengujian yang dilakukan adalah pengujian kuat tekan beton. Pengujian dilakukan pada saat beton berumur 7 , 14, 28 hari. Pengujian dilakukan di Laboratorium Bahan Bangunan Teknik Sipil Fakultas Teknik Universitas Katolik Soegijapranata.

c. Pembahasan

Analisis data yang dilakukan adalah dengan cara melihat hasil pengujian kuat tekan beton sudah sesuai dengan yang direncanakan dalam penelitian atau tidak.

\subsubsection{Tahap III}

Tahap ini merupakan tahap pengambilan dan penyusunan kesimpulan dari hasil penelitian yang telah dilakukan serta pembahasan data. Selain ketiga hal tersebut, pada tahap ini terdapat saran yang bertujuan untuk menunjang penelitian yang akan datang.

\section{ANALISIS DATA DAN PEMBAHASAN}

\subsection{Hasil Pengujian Bahan}

Pengujian bahan dilakukan dengan tujuan untuk mengetahui kualitas bahan yang akan digunakan sebagai campuran pembuatan beton. Pengujian yang dilakukan pada bahan-bahan tersebut mengacu pada standar-standar yang berlaku yaitu ASTM dan SNI. Berikut akan dijelaskan mengenai hasil dari masing-masing pengujian.

a. Analisis saringan agregat halus

Modulus kehalusan agregat halus (pasir pantai) dapat dihitung sebagai berikut:

Rumus Modulus Kehalusan

$=\frac{\sum \% \text { Tertahan Kumulatif }\left(\mathrm{no} \frac{3}{8}-200\right)}{100}$

Hasil pengujian analisis saringan agregat halus dapat dilihat pada Tabel 1 .
Tabel 1

Hasil Analisis Saringan Agregat Halus

\begin{tabular}{|c|c|c|c|c|}
\hline $\begin{array}{l}\text { Ukur } \\
\text { an } \\
\text { Ayak } \\
\text { an }\end{array}$ & $\begin{array}{c}\text { Berat } \\
\text { Tertah } \\
\text { an }\end{array}$ & $\begin{array}{l}\text { Tertah } \\
\text { an }\end{array}$ & $\begin{array}{c}\text { Tertah } \\
\text { an } \\
\text { Kumul } \\
\text { atif }\end{array}$ & $\begin{array}{c}\text { Lolos } \\
\text { Kumul } \\
\text { atif }\end{array}$ \\
\hline$(\mathrm{mm})$ & (gr) & $(\%)$ & $(\%)$ & $(\%)$ \\
\hline- & 0,000 & 0,000 & 0,000 & 0,000 \\
\hline 9,500 & 0,00 & 0 & 0,000 & 0,000 \\
\hline 4,750 & 1,000 & 0,19 & 0,191 & 99,809 \\
\hline 2,360 & 4,500 & 0,8 & 1,053 & 98,947 \\
\hline 1,180 & $\begin{array}{c}78,20 \\
0\end{array}$ & $\begin{array}{c}14,98 \\
4\end{array}$ & 16,037 & 83,963 \\
\hline 0,600 & $\begin{array}{c}330,1 \\
00\end{array}$ & $\begin{array}{c}63,25 \\
0\end{array}$ & 79,287 & 20,713 \\
\hline 0,300 & $\begin{array}{c}107,0 \\
00\end{array}$ & $\begin{array}{c}20,50 \\
2\end{array}$ & 99,789 & 0,211 \\
\hline 0,150 & 0,800 & 0,150 & 99,939 & 0,061 \\
\hline 0,075 & 0,500 & 0,061 & 100 & 0,000 \\
\hline $\begin{array}{l}\text { Total } \\
\text { Berat }\end{array}$ & $\begin{array}{c}522,1 \\
00\end{array}$ & \multicolumn{3}{|c|}{$\begin{array}{l}\text { Modulus Kehalusan Butir } \\
\quad=3,96\end{array}$} \\
\hline
\end{tabular}

b. Analisis berat jenis dan penyerapan agregat halus

Hasil pengujian berat jenis dan penyerapan agregat halus dapat dirangkum dan dilihat pada Tabel. 2

Tabel 2

Hasil Pengujian Berat Jenis dan Penyerapan Agregat Halus

\begin{tabular}{lc}
\hline \multicolumn{1}{c}{ Keterangan } & $\begin{array}{c}\text { Hasil } \\
\text { Percobaan }\end{array}$ \\
\hline $\begin{array}{l}\text { Apparent Specific. } \\
\text { Gravity }\left(\mathrm{gr} / \mathrm{cm}^{3}\right)\end{array}$ & 2,998 \\
\hline $\begin{array}{l}\text { Bulk Specific. Gravity } \\
\text { Kondisi Kering }\left(\mathrm{gr} / \mathrm{cm}^{3}\right)\end{array}$ & 1,324 \\
\hline $\begin{array}{l}\text { Bulk Specific. Gravity } \\
\text { Kondisi SSD }\left(\mathrm{gr} / \mathrm{cm}^{3}\right)\end{array}$ & 1,883 \\
\hline \% Penyerapan Air & 42,166 \\
\hline c. Analisis kadar air agregat halus dan \\
agregat kasar \\
$\begin{array}{l}\text { Hasil kadar air yang dimiliki agregat } \\
\text { halus (pasir pantai) adalah: }\end{array}$
\end{tabular}


Tabel 3

Hasil Pengujian Berat Jenis dan Penyerapan Agregat Halus

\begin{tabular}{ccc}
\hline A & Berat Wadah & 102,5 gr \\
\hline B & $\begin{array}{c}\text { Berat Wadah }+ \\
\text { Benda Uji }\end{array}$ & 1151,7 gr \\
\hline C & Berat Benda Uji & 1049,2 gr \\
\hline D & $\begin{array}{c}\text { Berat Benda Uji } \\
\text { Kering }\end{array}$ & 909,4 gr \\
\hline E & Kadar Air & $15,373 \%$ \\
\hline
\end{tabular}

Hasil kadar air yang dimiliki agregat kasar (karang) adalah:

Tabel 4

Hasil Pengujian Berat Jenis dan Penyerapan Agregat Kasar

\begin{tabular}{ccc}
\hline A & Berat Wadah & 70,8 gr \\
\hline B & $\begin{array}{c}\text { Berat Wadah }+ \\
\text { Benda Uji }\end{array}$ & 578,6 gr \\
\hline C & Berat Benda Uji & 507,8 gr \\
\hline D & $\begin{array}{c}\text { Berat Benda Uji } \\
\text { Kering }\end{array}$ & 458,5 gr \\
\hline E & Kadar Air & $10,752 \%$ \\
\hline
\end{tabular}

d. Analisis Saringan Agregat Kasar

Hasil pengujian analisis saringan agregat kasar dapat dilihat pada Tabel 5.

Tabel 5

Hasil Analisis Saringan Agregat Kasar

\begin{tabular}{|c|c|c|c|c|c|}
\hline $\begin{array}{l}\text { Ukuran } \\
\text { Ayakan }\end{array}$ & $\begin{array}{l}\text { Berat } \\
\text { Terta } \\
\text { han }\end{array}$ & $\begin{array}{c}\text { Terta } \\
\text { han }\end{array}$ & $\begin{array}{l}\text { Tertahan } \\
\text { Kumulatif }\end{array}$ & $\begin{array}{c}\text { Lolos } \\
\text { Kumu } \\
\text { latif }\end{array}$ & $\begin{array}{c}\text { Spesifi } \\
\text { kasi } \\
\text { ASTM } \\
\text { C33-90 }\end{array}$ \\
\hline$(\mathrm{mm})$ & $\begin{array}{c}\text { (gram } \\
\text { ) }\end{array}$ & $(\%)$ & $(\%)$ & $(\%)$ & \\
\hline- & 0,000 & $\begin{array}{c}0,00 \\
0 \\
\end{array}$ & 0,000 & 0,000 & \\
\hline 9,500 & 582,5 & $\begin{array}{c}60,1 \\
38 \\
\end{array}$ & 60,138 & $\begin{array}{c}39,86 \\
2 \\
\end{array}$ & $20-55$ \\
\hline 4,750 & 386,1 & $\begin{array}{c}39,8 \\
62\end{array}$ & 60,138 & 0,000 & $0-10$ \\
\hline $\begin{array}{l}\text { Total } \\
\text { Berat }\end{array}$ & 968,6 & Mo & is Keh & Buti &, 6014 \\
\hline
\end{tabular}

e. Analisis Keausan Agregat Kasar Dengan Mesin Los Angeles Hasil pengujian analisis keausan agregat kasar dengan mesin Los Angeles.
Tabel 6

Hasil Analisis Keausan Agregat Kasar Dengan Mesin Los Angeles

\begin{tabular}{ccc}
\hline A & Benda Uji & 500 gr \\
\hline B & $\begin{array}{c}\text { Benda Uji Sesudah } \\
\text { Diuji }\end{array}$ & $\begin{array}{c}1151,7 \\
\text { gr }\end{array}$ \\
\hline C & Keausan & $93,04 \%$ \\
\hline \multicolumn{2}{c}{ Berdasarkan perhitungan } & yang telah
\end{tabular}
dilakukan di atas dapat diketahui bahwa keausan total dari agregat kasar (koral) sebesar 93,04\%. Berdasarkan PUBI (Persyaratan Umum Bahan Bangunan Indonesia) 1982 Pasal 12 "Syarat fisik kerikil bagian yang hancur bila diuji memakai mesin los Angeles tidak lebih dari 50\% berat" jadi agregat kasar (karang) diatas tidak memenuhi syarat sebagai bahan bangunan.

f. SEM EDX Agregat Halus (Pasir Pantai) dan Agregat Kasar (Karang) SEM (Scanning Electron Microscope) merupakan suatu uji yang dilakukan untuk mengetahui detail morfologi atau topografi sampel dan obyek diamati secara tiga dimensi, sedangkan EDX (Energy Dispersive X-ray Spectroscopy) digunakan untuk mengetahui komposisi unsur dan sebaran unsur yang terdapat pada suatu (sampel). EDX dapat dilakukan pada daerah yang kecil (titik). Tahap pengujian SEM EDX dibagi menjadi 5 tahap, yaitu menghidupkan SEM, preparasi sampel, pemasangan sampel, observasi dan prosedur penggunaan EDS.

Hasil uji SEM EDX agregat kasar (karang) dan agregat halus (pasir pantai) dapat dilihat pada Tabel 7. 
Tabel 7

Hasil Pengujian SEM EDX

Agregat Kasar (Karang)

dan Agregat Halus (Pasir Pantai)

\begin{tabular}{|c|c|c|c|}
\hline No. & $\begin{array}{c}\text { Nama } \\
\text { Sampel } \\
\text { Uji }\end{array}$ & Komponen & $\begin{array}{c}\text { Hasil } \\
\text { Analisis } \\
(\% \\
\text { Berat }) \\
\end{array}$ \\
\hline \multirow[t]{9}{*}{1} & Karang & Karbon (C) & 28,97 \\
\hline & & $\begin{array}{l}\text { Magnesium } \\
\text { Oksida } \\
(\mathrm{MgO})\end{array}$ & 2,78 \\
\hline & & $\begin{array}{l}\text { Alumina } \\
\left(\mathrm{Al}_{2} \mathrm{O}_{3}\right)\end{array}$ & 18,14 \\
\hline & & $\begin{array}{l}\text { Silika } \\
\text { Dioksida } \\
\left(\mathrm{SiO}_{2}\right)\end{array}$ & 34,00 \\
\hline & & $\begin{array}{l}\text { Kalium } \\
\text { Oksida } \\
\left(\mathrm{K}_{2} \mathrm{O}\right)\end{array}$ & 0,93 \\
\hline & & $\begin{array}{l}\text { Kalsium } \\
\text { Oksida } \\
(\mathrm{CaO})\end{array}$ & 8,63 \\
\hline & & $\begin{array}{l}\text { Titanium } \\
\text { Dioksida } \\
\left(\mathrm{TiO}_{2}\right)\end{array}$ & 0,68 \\
\hline & & $\begin{array}{l}\text { Mangan } \\
\text { Oksida } \\
(\mathrm{MnO})\end{array}$ & 0,50 \\
\hline & & $\begin{array}{ll}\text { Besi } & \text { (II) } \\
\text { Oksida } & \\
(\mathrm{FeO}) & \\
\end{array}$ & 5,37 \\
\hline & $\begin{array}{l}\text { Pasir } \\
\text { Pantai }\end{array}$ & Karbon $(\mathrm{C})$ & 30,61 \\
\hline & & $\begin{array}{l}\text { Natrium } \\
\text { Oksida } \\
\left(\mathrm{Na}_{2} \mathrm{O}\right)\end{array}$ & 0,92 \\
\hline & & $\begin{array}{l}\text { Alumina } \\
\left(\mathrm{Al}_{2} \mathrm{O}_{3}\right)\end{array}$ & 2,32 \\
\hline & & $\begin{array}{l}\text { Silika } \\
\text { Dioksida } \\
\left(\mathrm{SiO}_{2}\right)\end{array}$ & 2,45 \\
\hline
\end{tabular}

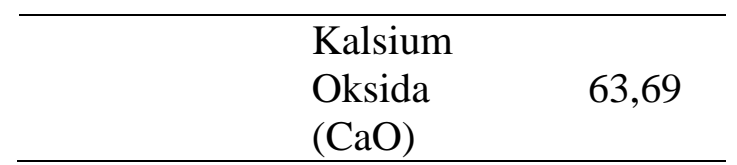

(Sumber: Unit Pelaksana Teknis Laboratorium Terpadu Universitas Diponegoro, 2019)

\subsection{Perhitungan Campuran Beton}

Campuran adukan beton direncanakan memiliki kuat hancur K 300 . Langkah perhitungan perencanaan beton yang direncanakan adalah sebagai berikut:

a. Penakaran komponen beton yang direncanakan sebelumnya.

Perbandingan volume semen, karang, dan pasir yang penulis tetapkan adalah 0,7 semen : 1 karang : 1,3 pasir dari volume silinder rencana yang memiliki tinggi $20 \mathrm{~cm}$ dan diameter $10 \mathrm{~cm}$.

Rumus perhitungan volume yang digunakan:

volume benda uji silinder $=$ perbandingan $\times \pi \times r^{2} \times t$

g. Perhitungan volume air

Peraturan yang digunakan adalah ACI 211-1-91. Berdasarkan peraturan tersebut, faktor air yang dipilih adalah 0,45 karena beton yang direncanakan merupakan struktur yang terpapar air laut dan garam sulfat sesuai dengan hasil uji SEM EDX pada agregat kasar dan halus.

Rumus faktor air semen sebagai berikut:

$$
\text { Faktor Air Semen }=\frac{\text { Volume Air }}{\text { Volume Semen }}
$$

Dari perhitungan volume air yang digunakan untuk penelitian ini adalah $472 \mathrm{~cm}^{3}$. Tetapi pada pelaksanaannya volume air yang digunakan adalah 1000 $\mathrm{cm}^{3}$, karena agregat kasar yang bersifat porus dapat menyerap setengah air yang digunakan untuk pencampuran 


\subsection{Pembuatan Benda Uji}

Pembuatan benda uji dibagi menjadi 3 tahap. yaitu pembuatan benda uji silinder dengan konsentrasi Polymer Concrete konsentrasi 0\% (tahap I), Polymer Concrete konsentrasi 2\% (tahap II), dan Polymer Concrete konsentrasi 4\% (tahap III).

\subsection{Perawatan Benda Uji}

Acuan yang digunakan untuk curing benda uji adalah (SNI) 2493:2011. Tujuan curing adalah menghindari efek samping panas hidrasi yaitu crack pada beton atau biasa disebut dengan keretakan pada beton. Benda uji dibuka setelah 24 jam \pm 8 jam setelah pencetakan. Setelah dibuka benda uji harus dirawat basah dengan temperatur $23^{\circ} \mathrm{C} \pm 1,7^{\circ} \mathrm{C}$.

\subsection{Pengujian Kuat Tekan Beton}

Uji kuat tekan beton yang dilakukan pada penelitian ini dilakukan pada saat beton (benda uji) berumur 7, 14, dan 28 hari di Laboratorium Bahan Bangunan Program Studi Teknik Sipil Fakultas Teknik Universitas Katolik Soegijapranata.

\subsubsection{Berat Massa Volume Beton Benda Uji Silinder}

Berat massa volume beton dapat diartikan sebagai perbandingan antara berat benda uji beton yang ditimbang pada saat beton berumur 7, 14, dan 28 hari. Rumus perhitungan berat massa volume beton dengan benda uji silinder adalah sebagai berikut:

a. volume benda uji silinder $=\pi \times r^{2} \times t$

b. berat massa volume beton $=\frac{\text { Berat Benda Uji Silinder }}{\text { Volume Benda Uji Silinder }}$

Hasil berat massa volume beton rata-rata benda uji 1 sampai dengan 3 dengan konsentrasi $0 \%, 2 \%$, dan $4 \%$ pada waktu beton berumur 7 hari dapat dilihat pada Tabel 8 .

Tabel 8

Rata-Rata Berat Massa Volume Beton

\begin{tabular}{ccc}
\hline No. & $\begin{array}{c}\text { Umur } \\
\text { (hari) }\end{array}$ & $\begin{array}{c}\text { Rata-Rata Berat } \\
\text { Massa Volume Beton } \\
\left(\mathrm{kg} / \mathrm{m}^{3}\right)\end{array}$ \\
\hline 1 & 7 & 1966,73755 \\
\hline 2 & 14 & 1856,688 \\
\hline 3 & 28 & 1828,025 \\
\hline
\end{tabular}

3.5.2. Hasil Pengujian Kuat Tekan Beton

Dari hasil pengujian kuat tekan yang dilakukan dengan menggunakan mesin Universal Testing Machine (UTM) didapatkan beban maksimum (pada saat benda uji mengalami keruntuhan akibat menerima beban) $\left(\mathrm{P}_{\max }\right)$.

\subsubsection{Perhitungan Kuat Tekan Beton}

Rumus yang digunakan untuk menghitung kuat tekan beton sebagai berikut:

a. Perhitungan luas penampang benda uji silinder (A)

$$
\mathrm{A}=\pi \times \mathrm{r}^{2}
$$

Keterangan :

$\mathrm{A}=$ luas penampang benda uji $\left(\mathrm{cm}^{2}\right)$

$\Pi=$ konstanta $(3,14)$

$\mathrm{r}=$ jari-jari benda uji silinder $(\mathrm{cm})$

b. Perhitungan kuat tekan benda uji silinder

$$
\text { Kuat tekan }=\frac{\text { Gaya Tekan Maksimum } \times 100}{\mathrm{~A}}
$$

c. Pengkonversian kuat tekan benda uji silinder ke benda uji kubus :

Kuat tekan silinder ke kubus $=\frac{\text { Kuat Tekan Silinder }}{0,83}$

d. Prediksi konversi kuat tekan benda $\mathrm{n}$ hari ke 28 hari

Kuat tekan n hari ke 28 hari $=\frac{\text { Kuat Tekan Kubus } 7 \text { Hari }}{\text { koefisien }}$ 
Data hasil uji kuat tekan beton rata-rata dapat dilihat pada data Tabel 9.

3.5.2.2. Analisis Kuat Tekan Beton Berdasarkan SK SNI T-15-199003 dijelaskan mengenai perkiraan/ persentase perkembangan kuat tekan beton berdasarkan umur beton. Data pada SK SNI T-15-1990-03 dapat digunakan untuk menghitung kuat tekan beton mutu K 300 $\left(300 \mathrm{~kg} / \mathrm{cm}^{2}\right)$ dengan berbagai variasi umur beton. Berikut adalah kuat tekan beton mutu K $300 \quad\left(300 \quad \mathrm{~kg} / \mathrm{cm}^{2}\right)$ berdasarkan umur beton:

1. Beton Berumur n Hari

Kuat tekan $\mathrm{n}$ hari $=300 \times$ koefisien

Rumus tersebut digunakan sebagai acuan untuk mengetahui mutu beton yang dihasilkan dari penelitian sesuai dengan mutu K 300. Tabel 9 merupakan perbandingan kuat tekan rata-rata hasil penelitian dengan kuat tekan beton mutu $\mathrm{K}$ 300 berdasarkan umur beton.

Tabel 9

Perbandingan Kuat Tekan Rata-Rata

Hasil Penelitian Dengan Kuat Tekan

Beton Mutu K 300 Berdasarkan Umur

Beton.

\begin{tabular}{ccccc}
\hline & & & \multicolumn{2}{c}{ Kuat Tekan } \\
\cline { 3 - 5 } No & $\begin{array}{c}\text { Umur } \\
\text { (hari) }\end{array}$ & $\begin{array}{c}\text { Kadar } \\
\text { Polcon } \\
(\%)\end{array}$ & $\begin{array}{c}\text { Hasil } \\
\text { Penelitian } \\
\text { Rata-Rata } \\
\left(\mathrm{kg} / \mathrm{cm}^{2}\right)\end{array}$ & $\begin{array}{c}\text { Mutu } \\
\text { K }\end{array}$ \\
$\begin{array}{ccccc}(\mathrm{kg} / \\
\left.\mathrm{cm}^{2}\right)\end{array}$ \\
\hline 1 & 7 & 0 & 117,6083 & 195 \\
\hline & & 2 & 148,2887 & 195 \\
\hline & & 4 & 138,062 & 195 \\
\hline 2 & 14 & 0 & 138,062 & 264 \\
\hline & & 2 & 255,67 & 264 \\
\hline 3 & 28 & 4 & 224,98 & 264 \\
\hline & & 2 & 138,062 & 300 \\
\hline & & 4 & 245,443 & 300 \\
\hline
\end{tabular}

Berdasarkan tabel di atas dapat diketahui bahwa beton yang dihasilkan oleh hasil penelitian tidak memenuhi mutu K 300 , dapat diketahui dari kuat tekan yang dihasilkan tidak sesuai dengan kuat tekan mutu K 300 pada umur beton yang telah ditentukan.

\subsection{Pola Retak Pada Benda Uji Silinder}

Pada pengujian kuat tekan beton dapat diketahui pola retak yang terjadi pada beton akibat gaya tekan aksial. Berdasarkan pengujian yang dilakukan dapat disimpulkan bahwa pola keretakan yang terjadi hampir seragam pada bagian samping atas lalu secara diagonal membelah beton menjadi dua. Oleh karena itu dapat disimpulkan bahwa beton mengalami retak geser.

\section{PENUTUP}

\subsection{Kesimpulan}

Kesimpulan yang dapat diambil setelah melakukan penelitian kajian kuat tekan beton dengan agregat kasar (karang), agregat halus (pasir pantai), dan admixture polymer concrete yaitu:

1. Agregat halus pasir pantai mempunyai modulus kehalusan 3,96 dan termasuk jenis pasir kasar. Agregat halus ini dapat digunakan sebagai agregat halus pada beton akan tetapi

2. Agregat halus mempunyai persen penyerapan air $42,166 \%$, berat jenis dalam kondisi kering 1,324 $\mathrm{gr} / \mathrm{cm}^{3}$, dan berat jenis saat kondisi SSD (Saturated Surface Dry)sebesar 1,883 $\mathrm{gr} / \mathrm{cm}^{3}$, dan kadar air $15,373 \%$.

3. Agregat kasar memiliki keausan 93,04\% pada uji los angeles sehingga tidak memenuhi syarat fisik kerikil menurut PUBI (Persyaratan Umum 
Bahan Bangunan Indonesia) 1982 pasal 12 yaitu tidak lebih dari 50\% dan tidak bisa digunakan sebagai agregat kasar bangunan.

4. Pada uji SEM EDX agregat halus (pasir pantai) dan agregat kasar (karang) kedua agregat tersebut memiliki kandungan kalsium oksida $(\mathrm{CaO})$ yang berpengaruh negatif terhadap konstruksi beton.

5. Berat massa benda uji beton rata-rata pada umur 7 hari adalah 1966,737 $\mathrm{kg} / \mathrm{m}^{3}$, pada benda uji beton umur 14 hari berat benda uji adalah 1856,688 $\mathrm{kg} / \mathrm{m}^{3}$, sedangkan pada umur 28 hari berat rata-rata benda uji adalah $1828,025 \mathrm{~kg} / \mathrm{m}^{3}$ sehingga benda uji termasuk dalam kategori beton ringan.

6. Penggunaan admixture polymer concrete (polcon) meperbesar kuat tekan beton sebesar $\pm 50 \%$ akan tetapi pada konsentrasi lebih tinggi tidak berpengaruh pada lebih tingginya nilai kuat hancur beton tersebut.

7. Kuat tekan rencana yaitu K 300 tidak dapat tercapai karena didapatkan hasil rata-rata kuat tekan beton terbesar adalah 245,443 kg/cm ${ }^{2}$ dengan $\mathrm{f}_{\mathrm{c}}$ ' 20,3 MPa yang merupakan sampel beton 28 hari yang menggunakan admixture polymer concrete $2 \%$

8. Pola keretakan dari hasil penelitian ini adalah retak geser, terjadi karena beton tidak mampu menahan gaya geser yang diberikan

9. Keretakan pada beton terjadi sebagian besar karena hancurnya agregat kasar beton (karang). Hal ini membuktikan bahwa analisis keausan karang benar bahwa agregat kasar yang digunakan tidak memenuhi syarat sebagai bahan agregat kasar untuk beton.

\subsection{Saran} yaitu:
1. Pemilihan agregat kasar dan halus harus diperhatikan dengan benar agar agregat kasar dan halus memenuhi peraturan yang berlaku. Apabila agregat kasar dan halus tidak memenuhi syarat, adukan beton dapat diberi bahan tambah dengan konsentrasi paling efisien.

2. agregat kasar dan halus pada beton yang akan digunakan untuk struktur utama sebaiknya tidak menggunakan agregat kasar dengan material karang dan agregat halus dengan material pasir pantai. Beton dengan menggunakan material agregat kasar karang dan agregat halus pasir pantai dapat digunakan pada konstruksi non struktur contohnya seperti plat lantai dasar dan dinding.

3. Sebaiknya dalam penggunaan admixture polymer concrete pada proyek bangunan menggunakan konsentrasi 2\% karena konsentrasi 2\% paling efektif dan dapat mencapai kuat tekan beton yang optimal

4. Untuk mendapatkan kuat tekan beton yang lebih optimal sebaiknya pada material agregat halus dan kasar yang digunakan dilakukan penambahan pasir gunung untuk agregat halus dan kerikil untuk agregat kasar. Penambahan pasir gunung difungsikan agar menambah kualitas lekatan agregat halus sedangkan penambahan agregat kasar difungsikan untuk mengurangi keausan agregat kasar.

\section{DAFTAR PUSTAKA}

ACI 211-1-191: Standard Practice for Selecting Proportions for Normal, Heavyweight, and Mass Concrete. Diakses dari 
https://www.academia.edu/38504100

/ACI_211.1-

91_Standard_Practice_for_Selecting Proportions_for_Normal_Heavyweig ht_and_Mass_Concrete

Agregat halus kasar diperoleh dari situs internet

http://www.ilmusipil.com/agregat-

halus-kasar. Diunduh pada tanggal 30 April 2019, pukul 20.00 WIB.

ASTM C33-90: 90: Standar lolos kumulatif agregat kasar. Diakses dari https://www.academia.edu/35079603 /Designation_C33_C33M_13_Standa rd_Specification_for_Concrete_Aggr egates_1

Mannuela, Johanna Indah dan Cahyaningtyas, Novita. 2018. Kajian Kuat Lentur Balok Beton komposit dengan angkur baja tulangan.Universitas katolik Soegijapranata : Semarang.

Masruri, N. (1993). Pengaruh Garam Sulfat terhadap Beton dan Cara Pencegahannya. Jurnal Pemukiman Volume IX No 11-12.

Peranan air dalam pembuatan beton diperoleh dari situs internet https://dwikusumadpu.wordpress.co m/tag/faktor-air-semen/. Diunduh pada tanggal 30 April 2019, pukul 20.00 WIB.

Persyaratan Umum Bahan Bangunan di Indonesia (PUBI). 1982. Yayasan Lembaga Penyelidikan Masalah Bangunan. Bandung. Diakses dari http://lib.kemenperin.go.id/neo/detail. php?id=232848

Salim, Dafiuddin, (2012): Pengelolaan Ekosistem Terumbu Karang Akibat
Pemutihan (Bleaching) dan Rusak, 5 (2), 142-155.

SK SNI T-15-1990-03. (1990): Tata cara perhitungan struktur beton untuk bangunan gedung. Yayasan Lembaga Penyelidikan Masalah Bangunan. Bandung. Diakses dari https://www.academia.edu/19498777 /SKSNI_T-15-199103_Tata_Cara_Perhitungan_Struktur _Beton_Untuk_Bangunan_Gedung

SNI ASTM C136:2012: Analisis Saringan Agregat Kasar. Badan Standardisasi Nasional Indonesia. Bandung. Diakses dari http://sni.litbang.pu.go.id/image/sni/i si/sni-astm-c136-2012.pdf

SNI 03-1968-1990. (1990): Metode pengujian analisis saringan Agregat halus dan kasar. Badan Standardisasi Nasional Indonesia. Bandung. Diakses dari http://staffnew.uny.ac.id/upload/1322 56207/pendidikan/sni-03-19681990.pdf

SNI 03-1970-1990: Metode pengujian berat jenis dan penyerapan air agregat halus. Badan Standardisasi Nasional Indonesia. Bandung. Diakses dari http://staffnew.uny.ac.id/upload/1322 56207/pendidikan/sni-03-19701990.pdf

SNI 03-1971-1990. (1990): Metode pengujian kadar air agregat. Badan Standardisasi Nasional Indonesia. Bandung. Diakses dari https://dokumen.tips/documents/sni03-1971-1990-569fef3b3edcc.html

SNI 03-1974-1990. (1990): Metode pengujian kuat tekan beton. Badan Standardisasi Nasional Indonesia. 
Bandung. Diakses dari https://dokumen.tips/download/link/s ni-03-1974-1990-metode-pengujiankuat-tekan-beton

SNI 03-2493-1991. (1991): Metoda pembuatan dan perawatan benda uji beton di laboratorium. Badan Standardisasi Nasional Indonesia. Bandung. Diakses dari https://www.scribd.com/document/23 2760595/SNI-03-2493-1991-pdf

SNI 03-2417-1991. (1991): Metode Pengujian Keausan Agregat Dengan Mesin Abrasi Los Angeles. Badan Standarisasi Nasional. Bandung. Diakses dari https://dokumen.tips/download/link/s ni-03-2417-1991

SNI 03-2847-2002. (2002): Tata Cara Pehitungan Struktur Beton Untuk Bangunan Gedung (Beta Version). Badan Standarisasi Nasional. Bandung. Diakses dari https://dokumen.tips/documents/sni03-2847-2002-tata-cara-perencanaanstruktur-beton-untuk-bangunangedung.html.

SNI 03-6815-2002. (2002): Tata Cara Mengevaluasi Hasil Uji Kekuatan Beton. Badan Standarisasi Nasional. Bandung. Diakses dari https://pdfslide.net/download/link/sni -03-6815-2002.

SNI 03-6820-2002. (2002): Spesifikasi Agregat Halus unruk Pekerjaan Adukan dan Plesteran dengan Bahan Dasar Semen. Badan Standarisasi Nasional. Bandung. Diakses dari https://dokumen.tips/documents/sni03-6820-2002-spesifikasi-agregathalus-untuk-pekerjaan-adukan-danplesteran.html
SNI 15-2049-2004. (2004). Semen Portland. Badan Standarisasi Nasional. Bandung. Diakses dari http://staffnew.uny.ac.id/upload/1322 56207/pendidikan/sni-15-20492004.pdf

SNI 1969-2008. (2008): Cara uji berat jenis dan penyerapan air agregat kasar.

Badan Standardisasi Nasional Indonesia. Bandung. Diakses dari https://dwikusumadpu.files.wordpres s.com/2013/03/sni-1969-2008.pdf

SNI 1970-2008. (2008): Cara uji berat jenis dan penyerapan air agregat halus.

Badan Standardisasi Nasional Indonesia. Bandung. Diakses dari http://sni.litbang.pu.go.id/image/sni/i si/sni-1970--2008.pdf

SNI 1972 :2008. (2008): Cara uji slump beton. Badan Standardisasi Nasional Indonesia. Bandung. Diakses dari https://dokumen.tips/download/link/s ni-1972-2008-cara-uji-slump-beton

SNI 1974:2011. (2011): Cara uji kuat tekan beton dengan benda uji silinder. Badan Standardisasi Nasional Indonesia. Bandung. Diakses dari http://staffnew.uny.ac.id/upload/1322 56207/pendidikan/sni-1974-2011.pdf

SNI 2493-2011: Tata Cara Pembuatan dan Perawatan Benda Uji Beton. Badan Standarisasi Nasional. Bandung. Diakses dari http://sni.litbang.pu.go.id/image/sni/i si/sni-2493-2011.pdf 